\title{
PENGARUH PENAMBAHAN RESORSINOL PADA PEMBUATAN PEREKAT LIKUIDA SABUT KELAPA
}

\author{
Mutiara Istiqomah, Netti Herlina \\ Departemen Teknik Kimia, Fakultas Teknik Universitas Sumatera Utara \\ Jl. Almamater Kampus USU Medan, 20155 Indonesia \\ Email : m_istiqomah31@yahoo.co.id
}

\begin{abstract}
Abstrak
Perekat likuida sabut kelapa adalah hasil reaksi antara lignin pada serbuk bahan yang digunakan dengan senyawa aromatik pada suhu tinggi sehingga diperoleh suatu larutan yang dapat digunakan sebagai perekat. Penelitian ini bertujuan untuk mengetahui karakteristik kualitas perekat likuida sabut kelapa (LSK) dan mengetahui pengaruh penambahan resorsinol pada pembuatan perekat LSK. Penelitian dilakukan dalam 3 tahap yaitu tahap I pembuatan partikel sabut kelapa, dimana pada tahap ini sabut kelapa dibuat kedalam partikel 100 mesh, tahap II pembuatan perekat LSK dimana pada tahap ini terdapat dua tahapan reaksi yaitu likuifikasi sabut kelapa dan polimerisasi, dan tahap III penambahan resorsinol kedalam perekat LSK. Variabel yang digunakan dalam penelitian ini adalah variabel penambahan kadar resorsinol sebesar 10, 20,30 persen berat . Variabel - variabel yang diamati yaitu analisa $\mathrm{pH}$, viskositas, spesific gravity, kadar padatan, kadar formaldehida bebas dan analisa senyawa dengan menggunakan FT-IR perekat LSK untuk kondisi tanpa penambahan resorsinol dan dengan penambahan 30\% resorsinol. Hasil penelitian menunjukkan bahwa penambahan resorsinol memberikan pengaruh pada perekat LSK yang dihasilkan, yaitu $\mathrm{pH}$ berkisar 12,6-10,6, viskositas 43,867- 131,712 cps, spesifik gravity 1,252-1,258, kadar padatan 46,67-80\%, kadar formaldehida 1,952-1,051\%. Hasil FT-IR perekat LSK menunjukkan adanya kemiripan gugus dengan resin fenol formaldehid, yaitu adanya gugus $\mathrm{OH}, \mathrm{C}=\mathrm{H}$ dari cincin aromatic, $\mathrm{C}-\mathrm{H}$ dari metilen, $\mathrm{C}-\mathrm{O}$ dari eter dan senyawa fenolik.
\end{abstract}

Kata kunci: sabut kelapa, fenol, formaldehid, resorsinol, perekat likuida sabut kelapa.

\begin{abstract}
Liquid adhesive coconut coir is the result of a reaction between lignin powder material used with aromatic compounds at high temperatures in order to obtain a solution that can be used as an adhesive. This study aims to investigate the characteristics of liquid adhesive of coconut coir (LACC) qualities and determine the effect of resorcinol in the manufacture of adhesives LACC. The study was conducted in three phases: the first stage of coir manufacturing particles, which at this stage coir made into particles of 100 mesh, adhesive manufacturing second stage LACC which at this stage there are two stages of the liquefaction reaction coir and polymerization, and the third stage addition of resorcinol LACC into the adhesive. The variables used in this study is the addition of variable rate resorcinol at 10,20,30\% by weight. Variables - variables that were analyzed $\mathrm{pH}$, viscosity, spesific gravity, solid content, formaldehyde-free rate and compound analysis using FT-IR adhesive LACC to conditions without the addition of resorcinol and with the addition of $30 \%$ resorcinol. The results showed that the addition of resorcinol LACC influence on the resulting adhesive, which has a liquid form, the pH ranged from 12.6 to 10.6, 43,867-131.712 cps viscosity, specific gravity of 1.252 to 1.258 , solid content 46.67 to $80 \%$, from 1.952 to $1.051 \%$ formaldehyde content. FT-IR results showed similarity LACC adhesive force phenol formaldehyde resin, namely the presence of the $\mathrm{OH}$ group, $\mathrm{C}=\mathrm{H}$ of the aromatic ring, of methylene $\mathrm{CH}$, CO from ether and fenolic compound.
\end{abstract}

Keywords: cocofiber, phenol, formaldehyde, resorcinol, coconut liquid adhesive

\section{Pendahuluan}

Saat ini di Indonesia telah berdiri lebih dari ratusan industri pengolahan kayu (komposit) yang sebagian besar menggunakan perekat sintetik seperti fenol formaldehid (PF), urea formaldehid (UF), melamin formaldehid (MF). Perekat berbahan formaldehida merupakan perekat sintetis yang bahan bakunya diperoleh sebagai hasil olahan minyak bumi yang tidak dapat dipulihkan. Namun pada dasarnya pembuatan perekat tidak luput dari penggunaan formaldehida. Kelebihan penggunaan formaldehida dalam pembuatan perekat dapat menghasilkan sifat perekatan yang baik, namun beresiko besar menimbulkan emisi 
formaldehida yang sangat berbahaya bagi kesehatan tubuh [15].

$\mathrm{Pu}$, dkk (1991)mengembangkan suatu teknologi pembuatan perekat yaitu dengan mengkonversi serbuk kayu dengan proses kimia sederhana yang disebut proses likuifikasi [11]. Adanya penggunaan resorsinol pada dasarnya mampu mengikat gugus formaldehid yang tidak bereaksi dengan fenol. dimana reaksi antara resorsinol dan formaldehida dapat membentuk suatu resin yang bersifat termoset.

Adapun penelitian yang dilakukan yaitu pengaruh penambahan resorsinol pada pembuatan perekat likuida sabut kelapa. Bahan baku yang digunakan dalam penelitian ini adalah sabut kelapa, dimana penggunaan sabut kelapa ini masih memiliki nilai ekonomi yang rendah. Pada penelitian ini memvariasikan kadar penambahan resorsinol pada perekat likuida sabut kelapa (LSK) yang dihasilkan

\section{Teori}

Tanaman kelapa di Indonesia menyebar hampir diseluruh wilayah nusantara. Luas areal kelapa di Indonesia menurut Direktorat Jenderal Perkebunan Indonesia [5], pada tahun 2012 mencapai 3.787.724 Ha dengan total produksi diperkirakan sebanyak 3.176.223 ton, dan banyaknya limbah sabut kelapa yang dapat dihasilkan adalah sekitar 1,4 juta ton. Menurut United Coconut Association of the Philippines (UCAP), dari setiap butir kelapa dapat diperoleh sekitar $0,4 \mathrm{~kg}$ sabut yang mengandung sekitar $30 \%$ serat. Dengan demikian maka akan dihasilkan 0,42 juta ton serat kelapa.

Serat kelapa yang diperoleh dari bagian terluar buah kelapa (sabut kelapa) dari pohon kelapa (cocus nucifera) termasuk kedalam anggota keluarga Arecaceae (family palm), dimana serat ini tidak berbau, ringan, tebal, kuat dan memiliki ketahanan terhadap abrasi [7].

Perekat likuida adalah hasil reaksi antara lignin pada serbuk bahan yang digunakan dengan senyawa aromatik pada suhu tinggi sehingga diperoleh suatu larutan yang dapat digunakan sebagai perekat [2].

Mekanisme likuifikasi lignin yaitu Lignin terdegradasi menjadi turunan guaiacol dan phenolated dari hasil pembelahan ikatan $\beta-\mathrm{O}-4$ dengan fenol dengan adanya katalis atau tanpa katalis asam [10].

Lin, dkk (1997) [8], telah mempelajari serangkaian proses pencairan
Guaiacylglycerol- $\beta$-guaiacyl ether (GG) untuk memperjelas mekanisme likuifikasi lignin, mereka menemukan bahwa kelompok $\alpha$-hidroksil GG terlebih dahulu diserang oleh ion hidrogen $\left(\mathrm{H}^{+}\right)$dari katalis asam dan membentuk ikatan benzen, kemudian benzen berekasi dengan fenol melalui reaksi substitusi nukleofilik di para-posisi fenol untuk menghasilkan produk phenolated. Reaksi substitusi fenol pada $\mathrm{C} \gamma$ dari GG juga dapat membentuk phenolated. Dalam sistem likuifikasi pembelahan ikatan $\beta-O-4$ pada GG akan menghasilkan senyawa guaiacol dan coniferyl alcohol pada temperatur $250{ }^{\circ} \mathrm{C}$ tanpa menggunakan katalis asam.

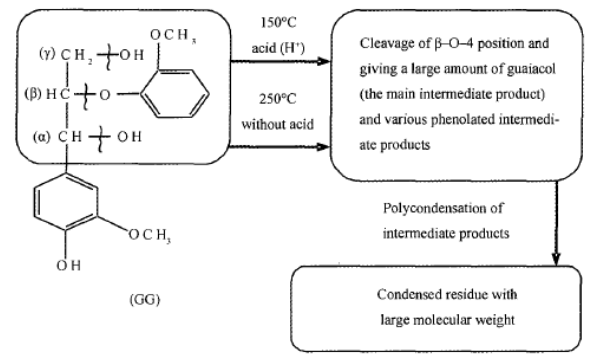

Gambar 1. Mekanisme Reaksi Likuifikasi Lignin Dengan Fenol dengan Katalis Asam dan Tanpa Katalis Asam [8]

Berikut ini adalah standarisasi kualitas perekat likuida mengacu pada standarisasi fenol formaldehida cair untuk kayu lapis

Tabel 1. Kualitas Fenol Formaldehida Cair Untuk Perekat Kayu Lapis [4]

\begin{tabular}{|c|c|c|}
\hline Parameter & Satuan & $\begin{array}{c}\text { SNI 06-4567- } \\
1998\end{array}$ \\
\hline Bentuk & - & Cair \\
\hline Kenampakan & & Merah \\
\hline & - & $\begin{array}{ll}\text { kehitaman } & \text { dan } \\
\text { bebas } & \text { dari }\end{array}$ \\
\hline $\mathrm{pH}\left(25^{\circ} \mathrm{C}\right)$ & - & $\begin{array}{l}\text { kotoran } \\
10-13\end{array}$ \\
\hline $\begin{array}{l}\text { Kekentalan } \\
\left(25^{\circ} \mathrm{C}\right)\end{array}$ & cps & $130-300$ \\
\hline $\begin{array}{l}\text { Specific gravity } \\
\left(25^{\circ} \mathrm{C}\right)\end{array}$ & - & $1,165-1,2$ \\
\hline Sisa penguapan & $\%$ & $40-45$ \\
\hline $\begin{array}{l}\text { Waktu gelatinasi } \\
\left(100^{\circ} \mathrm{C}\right)\end{array}$ & menit & $\geq 30$ \\
\hline $\begin{array}{l}\text { Formaldehid } \\
\text { bebas }\end{array}$ & $\%$ & $\leq 1 \%[3]$ \\
\hline
\end{tabular}

\section{Metodologi Penelitian}

Bahan baku yang digunakan dalam penelitian ini serat dari sabut kelapa berwarna 
cokelat. Bahan kimia yang digunakan adalah fenol, formaldehida $37 \%$, asam sulfat $98 \%$, $\mathrm{NaOH} 50 \%$, resorsinol, dan bahan kimia analisa lainnya.

Peralatan utama yang akan digunakan adalah ball mill, saringan ukuran 100 dan 140 mesh, labu leher tiga, refluks kondensor, penangas pasir, hot plate stirrer, oven, termometer dan peralatan gelas lainnya.

\section{Pembuatan Partikel Sabut Kelapa}

Serat kelapa dipisahkan dari sabut kelapa melalui proses perendaman selama 12 jam. Serat yang telah diperoleh dikeringkan dengan cara dijemur dan dimasukkan kedalam oven sampai kadar air sekitar $15 \%$. Serat yang telah dikeringkan dipotong dengan ukuran $\pm 30 \mathrm{~mm}$ dan digiling menggunakan ball mill dan disaring sampai diperoleh partikel ukuran 100 mesh. Partikel serat kelapa dikeringkan pada oven dengan suhu $60{ }^{\circ} \mathrm{C}$ sampai kadar air partikel $\pm 5 \%$ kurang lebih selama 20 menit.

\section{Tahap Pembuatan Perekat LSK}

Tahap pembuatan perekat LSK terdiri dari dua tahap yaitu tahap likuifikasi dan tahap polimerisasi.

Tahap likuifikasi sabut kelapa dimulai dengan memasukkan partikel sabut kelapa sebanyak 20 g kedalam labu leher tiga dan kemudian ditambahkan larutan $\mathrm{H}_{2} \mathrm{SO}_{4} 98 \%$ sebanyak $5 \mathrm{ml}$ (5\% dari berat fenol) dan diaduk selama 30 menit. Kedalam labu leher tiga kemudian ditambahkan larutan fenol sebanyak $100 \mathrm{ml}$ (5 kali berat partikel) dan diaduk dengan magnetic stirrer sampai homogeny. Campuran dipanaskan pada suhu $150{ }^{\circ} \mathrm{C}$ selama 1 jam dengan menggunakan pemanas pasir. Hasil reaksi didinginkan sampai suhu $30{ }^{\circ} \mathrm{C}$. hasil reaksi disebut dengan likuida sabut kelapa.

Tahap polimerisasi dimulai dengan mengatur $\mathrm{pH}$ dari likuida sabut kelapa yang dihasilkan dengan $\mathrm{NaOH} \quad 50 \%$ sampai mencapai $\mathrm{pH}$ 11. Larutan formaldehida $37 \%$ ditambahkan sebanyak 107,75 ml (fenol: formaldehid=1:2). Campuran tersebut diaduk sampai homogen. Kemudian campuran tersebut kemudian dipanaskan pada duhu $90^{\circ} \mathrm{C}$ selama 2 jam sambil diaduk sampai produk menjadi homogen dengan menggunakan hotplate stirrer. Hasil reaksi disebut dengan perekat likuida sabut kelapa.

\section{Tahap Penambahan Resorsinol kedalam Perekat LSK}

Perekat LSK yang dihasilkan divariasikan dengan penambahan resorsinol yaitu tanpa penambahan, dengan penambahan $10 \%, 20 \%$ dan $30 \%$ (b/b).

\section{Analisa Karakteristik Perekat LSK}

Analsa karakteristik perekat LSK meliputi analisa $\mathrm{pH}$, viskositas, specific gravity, solid content yang mengacu pada SNI 06-4567-1998 dan analisa kadar formaldehid bebas yang mengacu pada SNI 06-4565-1998 [3].

\section{Analisis Senyawa dengan FT-IR}

Analisis resin perekat dilakukan dengan mengidentifikasi gugus fungsi yang dimiliki resin. Contoh yang akan dianalisis dicampurkan dengan $\mathrm{KBr}$ dengan perbandingan $3: 1$. Campuran dibuat sampai homogen. Contoh discan dengan FTIR pada daerah $4000-500 \mathrm{~cm}^{-1}[13]$

\section{Hasil dan Pembahasan \\ pH Perekat LSK}

Pengaruh kadar penambahan resorsinol terhadap $\mathrm{pH}$ perekat LSK dapat dilihat pada gambar 3 .

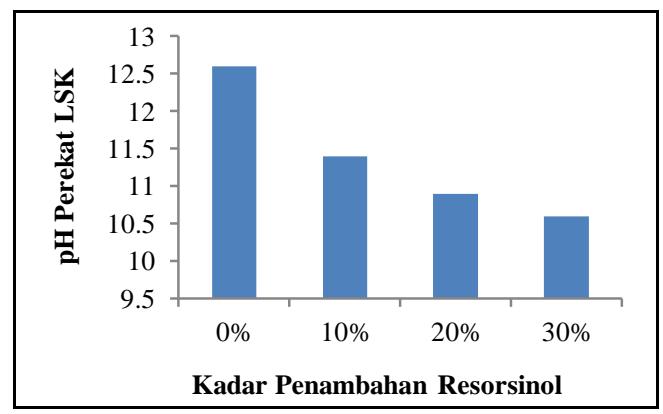

Gambar 3. Pengaruh Kadar Penambahan Resorsinol Terhadap pH Perekat LSK

Berdasarkan hasil yang didapat, terlihat bahwa semakin besar kadar penambahan resorsinol, pH LSK semakin menurun. Hal ini disebabkan oleh penggunaan resorsinol, dimana resorsinol $\left(\mathrm{C}_{6} \mathrm{H}_{6} \mathrm{O}_{2}\right)$ tersebut bersifat asam, sehingga semakin besar penggunaannya, maka akan menurunkan pH LSK [15]. Namun penggunaan resorsinol harus mempertimbangkan $\mathrm{pH}$ perekat yang akan dihasilkan nantinya, perekat memiliki nilai batas untuk $\mathrm{pH}$ sebesar 10-13 sehingga penggunaan diatas $30 \%$ akan menurunkan $\mathrm{pH}$ 
dan hal ini akan mempengaruhi kualitas dari perekat yang dihasilkan.

Dari data yang dihasilkan pH LSK yang diperoleh memenuhi standar SNI 064567-1998 yang mensyaratkan $\mathrm{pH}$ perekat sebesar $10-13$.

\section{Viskositas Perekat LSK}

Pengaruh kadar penambahan resorsinol terhadap viskositas perekat LSK dapat dilihat pada gambar 4 .

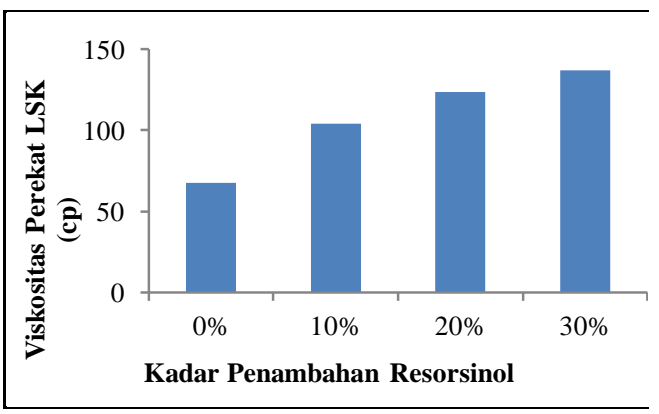

Gambar 4. Pengaruh Kadar Penambahan Resorsinol Terhadap Viskositas Perekat LSK

Nilai kekentalan perekat yang optimal akan membantu meningkatkan kualitas perekatan, sebagai akibat baiknya penetrasi perekat kedalam partikel [14].

Berdasarkan hasil yang didapat untuk perekat LSK dengan 0\%, 10\%, 20\% penambahan resorsinol, nilai viskositas yang dihasilkan belum memenuhi SNI 06-45671998. Namun untuk perekat LSK dengan penambahan $30 \%$ resorsinol memenuhi SNI 06-4567-1998. Penambahan resorsinol, meningkatkan kekentalan dari perekat LSK yang dihasilkan.

Penambahan resorsinol diatas $30 \%$ akan meningkatkan viskositas perekat LSK namun perlu diketahui bahwa viskositas yang tinggi memang akan mempersingkat pot-life (kemampuan menembus pori kayu) sangat pengaplikasiannya pada produk kayu tetapi akan lebih cepat mengeras daripada perekat yang encer, sehingga kualitas perekatannya relatif rendah [12].

\section{Specific Gravity}

Pengaruh kadar penambahan resorsinol terhadap spesific gravity perekat LSK dapat dilihat pada gambar 5.

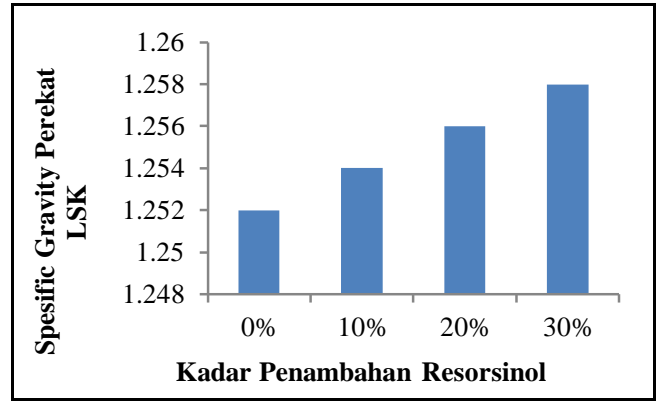

Gambar 5. Pengaruh Kadar Penambahan Resorsinol Terhadap Specific Gravity Perekat LSK

Menurut Standar Nasional Indonesia tentang perekat fenol formaldehida [4], spesific gravity perekat pada suhu $25{ }^{\circ} \mathrm{C}$ adalah 1,165-1,2. Dari hasil penelitian spesific gravity perekat LSK yang diperoleh adalah berkisar 1,252-1,258 $\mathrm{g} / \mathrm{cm}^{3}$. Hal ini tidak sesuai dengan standar yang telah ditentukan. Hal ini mungkin disebabkan oleh proses likuifikasi yang digunakan pada pembuatan perekat LSK. Menurut Lin, dkk [8] proses likuifikasi dengan pelarut fenol dan katalis asam pada suhu $150{ }^{\circ} \mathrm{C}$ akan menghasilkan residu kondensasi dengan molekul yang besar.

\section{Kadar Padatan Perekat LSK}

Pengaruh kadar penambahan resorsinol terhadap kadar padatan perekat LSK dapat dilihat pada gambar 6 .

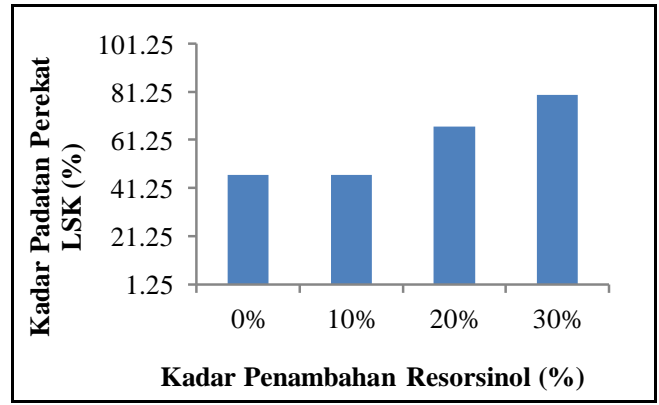

Gambar 6 Pengaruh Kadar Penambahan Resorsinol Terhadap Kadar Padatan Perekat LSK

Kadar padatan adalah suatu nilai yang menunjukkan kandungan resin padat yang tidak menguap selama proses pemanasan, jumlah resin padat tersebut mempengaruhi kekuatan papan partikel [9].

Berdasarkan hasil yang diperoleh terlihat bahwa semakin besar penambahan resorsinol kedalam perekat LSK maka kadar 
padatannya semakin meningkat. Meningkatnya kadar padatan suatu perekat, mengindikasikan bahwa penambahan resorsinol semakin menambah sempurnanya reaksi yang terjadi, sehingga molekulmolekul yang terkandung dalam resin semakin meningkat [12].

Namun hasil yang diperoleh tidak memenuhi SNI tentang perekat fenol formaldehida yang mensyaratkan kadar padatan berkisar $40-45 \%$. Hal ini disebabkan karena perekat LSK yang dihasilkan memanfaatkan lignin dalam pembuatannya, dimana lignin merupakan perekat alamiah antar sel [28] sehingga penggunaannya akan meningkatkan kadar padatan.

\section{Kadar Formaldehid Bebas Perekat LSK}

Hubungan kadar penambahan resorsinol terhadap kadar formaldehid bebas perekat LSK dapat dilihat pada gambar 7.

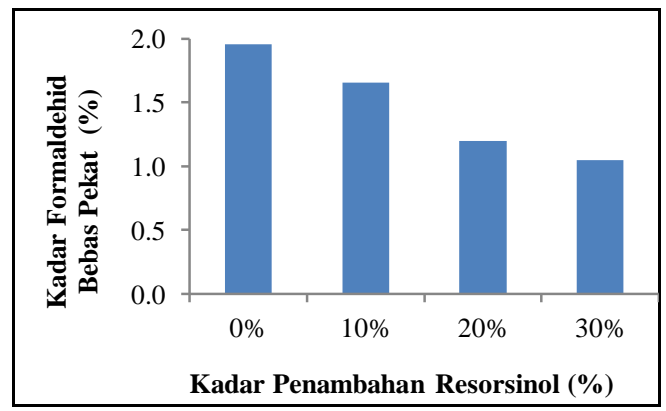

Gambar 7. Pengaruh Penambahan Kadar Resorsinol Terhadap Kadar Rormaldehid bebas Perekat LSK

Berdasarkan hasil yang diperoleh dapat dilihat bahwa pada penambahan $10 \%$ resorsinol mampu menurukan kadar formaldehida sebesar $15,37 \%$ dari sebelumnya, pada $20 \%$ penambahan resorsinol mampu menurunkan kadar formaldehid sebesar 38,47 \%, dan pada penambahan $30 \%$ resorsinol mampu menurunkan kadar formaldehid sebesar 46,16\%. Namun hasil yang diperoleh belum memenuhi Standar Nasional Indonesia tentang perekat Urea formaldehid yang mensyaratkan kadar formaldehid bebas $\leq 1 \%$. Banyaknya formaldehida bebas yang terdapat dalam perekat LSK yang dihasilkan tidak mampu diikat semua oleh resorsinol, sehingga masih meninggalkan formaldehid bebas.

\section{Karakteristik Senyawa Penyusun Perekat LSK Berdasarkan FT-IR}

Perekat LSK yang diuji merupakan perekat LSK yang dihasilkan dari penelitian dengan variasi tanpa penambahan resorsinol dan penambahan kadar resorsinol sebesar $30 \%$. Grafik FT-IR perekat LSK tanpa penambahan resorsinol dan dengan penambahan $30 \%$ resorsinol dapat dilihat pada gambar 8 dan gambar 9 .

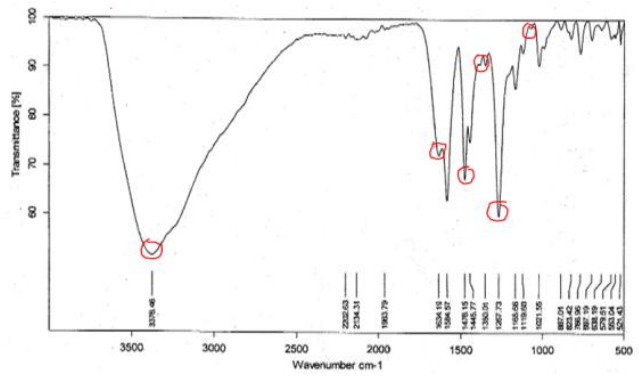

Gambar 8. Grafik FT-IR Perekat LSK Tanpa Penambahan Resorsinol

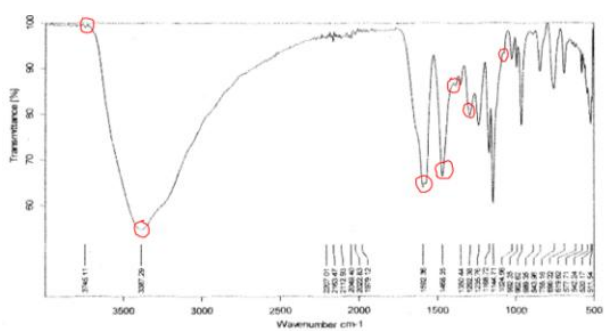

Gambar 9. Grafik FT-IR Perekat LSK dengan Penambahan 30\% Resorsinol

Berikut ini adalah pencirian gugus dari perekat LSK tanpa penambahan resorsinol dan dengan penambahan $30 \%$ resorsinol.

Tabel 2. Pencirian gugus fungsi perekat LSK

\begin{tabular}{|c|c|c|c|}
\hline \multicolumn{2}{|c|}{ Bil. Gelombang ( $\left.\mathrm{Cm}^{-1}\right)$ Pada Penelitian } & \multirow{2}{*}{$\begin{array}{c}\text { Standar Kisaran } \\
\text { Pita Serapan }\end{array}$} & \multirow{2}{*}{$\begin{array}{c}\text { Keterangan Gugus } \\
\text { Fungsi }\end{array}$} \\
\hline O\% Resorsinol & $30 \%$ Resorsinol & & \\
\hline . & 3745,11 & $3650-3600^{*}$ & Uluran 0 -H bebas \\
\hline 3376,46 & 3387,29 & $3400-3200$ & uluran $0-\mathrm{H}$ \\
\hline 1634,19 & - & $1680-1600$ & uluran $C=C$ \\
\hline - & $1592,36-1468,35$ & $1600-1475^{* * *}$ & vibrasi $C=C$ aromatik \\
\hline $1445,77-1350,01$ & 1350,44 & $1463-1370$ & $\mathrm{C}-\mathrm{H}$ dari metilen \\
\hline $1267,73-1021,55$ & $1292,38-1024,96$ & $1300-1000$ & $\begin{array}{l}\text { C-O dari eter dan } \\
\text { senyawa fenolik }\end{array}$ \\
\hline
\end{tabular}

$[6]^{*},[16]^{* *},[13]$.

Berdasarkan gambar 9. terlihat bahwa pita absorpsi $\mathrm{OH}$ yang mengindikasikan senyawa fenolik bebas muncul pada frekuensi 
$3745,11 \mathrm{~cm}^{-1}$. Adapun ikatan $\mathrm{O}-\mathrm{H}$ yang muncul tersebut merupakan ikatan $\mathrm{O}-\mathrm{H}$ yang berasal dari senyawa resorsinol yang masih tersisa.

Pita absorpsi $\mathrm{OH}$ yang mengindikasikan senyawa fenolik muncul pada frekuensi $3376,46 \mathrm{~cm}^{-1}$ (gambar 8) dan 3387,29 $\mathrm{cm}^{-1}$ (gambar 9).

Menurut young [16] pita absorbansi yang mengindikasikan ikatan $\mathrm{C}=\mathrm{C}$ muncul pada frekuensi $1680-1600 \mathrm{~cm}^{-1}$ untuk alkena dan 1600 dan $1475 \mathrm{~cm}^{-1}$ untuk cincin aromatik. Dapat terlihat pada gambar 10. pita absorpsi gugus $\mathrm{C}=\mathrm{C}$ untuk cincin aromatik muncul pada frekuensi 1592,36 dan 1468,35 $\mathrm{cm}^{-1}$. Menurut risfaheri, et al [13], pita yang muncul pada wilayah 1.463-1370 $\mathrm{cm}^{-1}$ mengindikasikan adanya gugus $\mathrm{C}-\mathrm{H}$ dari metilen dan pada wilayah $1.300-1.000 \mathrm{~cm}^{-1}$ mengindikasikan adanya gugus $\mathrm{C}-\mathrm{O}$ dari eter dan senyawa fenolik pada wilayah 1.260$1.000 \mathrm{~cm}^{-1}$.

Berdasarkan gambar, pita yang muncul pada wilayah $1445,77-1350,01 \mathrm{~cm}^{-1}$ (gambar 8) dan 1350,44 $\mathrm{cm}^{-1}$ (gambar 9) mengindikasikan adanya gugus $\mathrm{C}-\mathrm{H}$ dari metilen, dan pada wilayah 1267,73$1021,55 \mathrm{~cm}^{-1}$ (gambar 8) dan 1292,38$1024,96 \mathrm{~cm}^{-1}$ (gambar 8) mengindikasikan adanya gugus C-O dari eter dan pada wilayah 1235,76-1024,96 $\mathrm{cm}^{-1}$ (gambar 9) juga mengindikasikan adanya gugus $\mathrm{C}-\mathrm{O}$ dari senyawa fenolik.

Berdasarkan gambar 8 dan gambar 9 grafik FT-IR pada rentang gelombang 4000$500 \mathrm{~cm}^{-1}$ diatas dapat terlihat bahwa gugus gugus pada perekat LSK tanpa penambahan resorsinol dan penambahan $30 \%$ resorsinol memiliki kemiripan dengan gugus - gugus pada resin fenol formaldehid standar yaitu memiliki gugus $\mathrm{OH}, \mathrm{C}=\mathrm{H}$ dari cincin aromatik, C-H dari metilen, C-O dari eter dan senyawa fenolik.

\section{Kesimpulan}

Berdasarkan hasil penelitian dapat disimpulkan bahwa Pengaruh penambahan resorsinol pada pembuatan perekat LSK terbaik pada penambahan $30 \%$ berat resorsinol.

\section{Daftar Pustaka}

[1] Ahmad Werdhi Kausar, "Kualitas Likuida Tandan Kosong Sawit (Elaeis Guineensis Jacq) Dengan Perlakuan Perendaman N-Heksane Dan Pemberian Resorsinol", Skripsi,
Program Sarjana Fakultas Kehutanan IPB, Bogor, 2012.

[2] Alvin Andro Meda, "Kualitas Komposit Dan Likuida Limbah Sabut Kelapa Dengan Fortifikasi Perekat Poliuretan", Skripsi, Program Sarjana Fakultas kehutanan, Bogor, 2006.

[3] Badan Standarisasi Nasional, SNI 060060-1998 "Tentang Urea Formaldehida Cair Untuk Perekat Kayu Lapis",Jakarta: BSN, 1998.

[4] Badan Standarisasi Nasional, "SNI 064567-1998 Tentang Fenol Formaldehida Cair Untuk Perekat Kayu Lapis”, Jakarta: BSN, 1998.

[5] Direktorat Jenderal Perkebunan, "Data Lima Tahun Subsektor Perkebunan (2008-2012)", www.deptan.gi.id, 2013.

[6] Donald L. Pavia, Gary M. Lampman, George S. Kriz, ." Introduction to Spectroscopy, Washington : Thomson Learning,2001

[7] Jorge Rencoret, John Ralph, Gisela Marques, Ana Gutierrez, Angel T. Martinez Dan Jose C. Del Rio,"Structural Characterization Of Lignin Isolated From Coconut (Cocos Nucifera) Coir Fibers", Journal Or Agricultural And Food Chemistry,61, 2013 : 2434-2445.

[8] Lin L Z, Yao Y G, Yoshioka M, Shiraishi N, "Liquefaction Mechanism Of Lignin In The Presence Of Phenol At Elevated Temperature Without Catalysts: Studies On B-O-4 Lignin Model Compound. 2. Reaction Pathway", Holzforschung, 51(4), 1997: 325-332.

[9] Marcelila Medynda, "Pengembangan Perekat Likuida Dari Limbah Kulit Buah Kakao ( Theobroma Cacao L.), Skripsi, Program Sarjana Falkutas Kehutanan USU, Medan, 2012.

[10] NIU Min, ZHAO Guang-Jie, Mehmet Hakki Alma, "Polycondensation Reaction And Its Mechanism During Lignocellulosic Liquefaction By An Acid Catalyst: A Review", Forestry Studies in China, Vo1.13, No.1, 2011; 71-79.

[11] $\mathrm{Pu} \mathrm{S}$, Yoshioka M, Tanihara Y Shiraishi N, "Liquefaction Of Wood In Phenol And Its Application To Adhesive", Kyoto : Kyoto University, 1991.

[12] Ridwanti Batubara, Pemanfaatan Lignin Dari Lindi Hitam Sebagai Bahan Baku Perekat Lignin 
Resorsinol Formaldehida (LRF), Jurnal VISI (2009) 17 (2), ISSN 08530203, 2009 : 207-216.

[13] Risfaheri, et al,'Optimasi Komposisi Kardanol Dari Minyak Kulit Mete Sebagai Substitusi Fenol Dalam Formulasi Perekat Fenol Formaldehida",Jurnal Pascapanen, 2(1), 2005: 23-33.

[14] Surdiding Ruhendi, "Kualitas Papan Partikel Kenaf Menggunakan Perekat Likuisa Dengan Fortifikasi Melamin Formaldehid", Jurnal Ilmu Dan Teknologi Hasil Hutan 1(1): 34-44.

[15] Tito Sucipto, "Karakterisasi Partikel Dan Likuida Tandan Kosong Sawit", Tesis, Sekolah Pascasarjana IPB, Bogor, 2009.

[16] Young P.R, "basic Infrared Spectroscopy Organic Chemistry On Line".http://chipo.chem.uic.edu/wwe1 /ocol/spec/IR.htm, Diakses 9 Agustus 2014. 